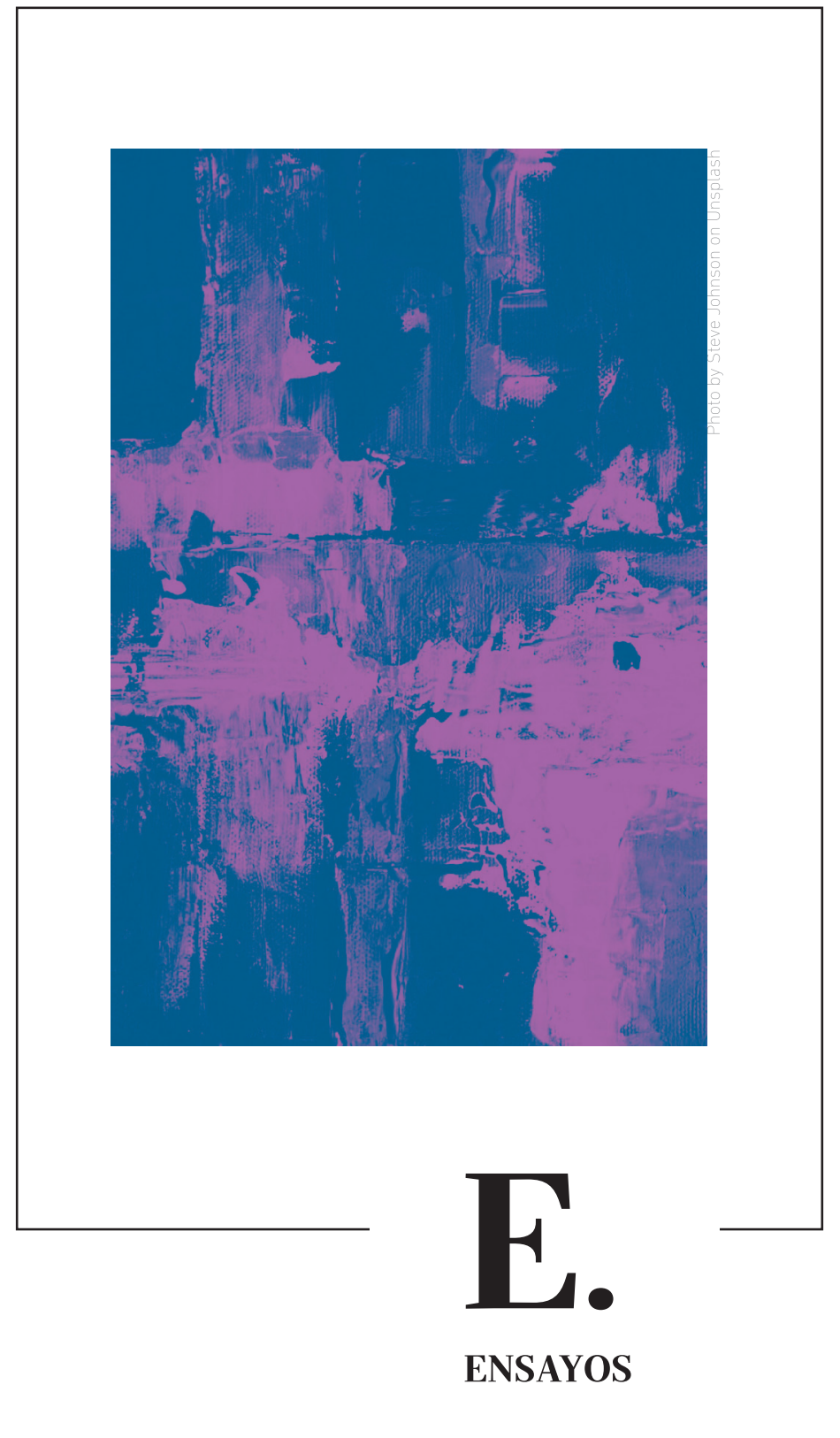




\title{
Enigmas de la Nueva corónica y buen gobierno de Guamán Poma de Ayala
}

\author{
Rocío QuisPe-Agnoli
}

En el 2001, a propósito del lanzamiento de la digitalización de la Nueva corónica y buen gobierno, Rolena Adorno presentó una revisión panorámica de estudios de la obra de Felipe Guamán Poma de Ayala en el último siglo y apuntó tres coyunturas cruciales en la recepción crítica de este texto. La primera fue el anuncio que hizo el bibliotecario alemán Richard Pietschmann, en 1908, de la existencia del manuscrito GKS 2232 $4^{\circ}$, número de catalogación de la crónica de Guamán Poma en la Biblioteca Real de Dinamarca. La obra del cronista andino había residido -y reside- en las colecciones especiales del fondo antiguo de dicha biblioteca por lo menos desde las últimas décadas del siglo XVIII. Pietschmann hizo público este hallazgo en el boletín de noticias de la Real Sociedad de Göttingen, Alemania, y, cuatro años más tarde, en las Actas del Congreso de Americanistas de Londres de 1912 (1913). El segundo momento fundamental que Adorno apuntó a propósito de la recepción de la crónica andina fue la publicación del facsímil fotográfico del manuscrito completo en 1936. Esto fue llevado a cabo por el Instituto de Etnología de la Universidad de París bajo la dirección de Paul Rivet.

Tuvieron que pasar sesenta y cinco años para dar lugar a la tercera coyuntura que impacta hasta hoy en la difusión de este documento: la publicación en línea del facsímil digital de la crónica en su totalidad gracias a la iniciativa de la Biblioteca Real de Dinamarca y bajo la dirección de un equipo académico y técnico encabezado por Rolena Adorno. Este nuevo formato ha permitido no solo poner esta obra al alcance de los lectores de hoy, sino también ha puesto a disposición pública imágenes de alta resolución de cada página del manuscrito de tal manera que, gracias a las ampliaciones digitales que permiten visibilizarlas claramente, es posible examinar detalles que escapan al ojo común ${ }^{1}$. Esta contribución de la biblioteca que preserva la obra

1 Las páginas del manuscrito original miden 14.5 × 20.5 centímetros. Está empastado con una cubierta de cuero del siglo xIX que no hace fácil su consulta. La crónica tiene 1,189 páginas y, con estas dimensiones y 
de Guamán Poma, la ha hecho accesible para continuar su estudio y también para el público general con la consiguiente difusión de sus contenidos y la popularización de sus ilustraciones en diversas plataformas y formatos, algunos de los cuales menciono en la conclusión de este artículo.

Ahora bien, a estas coyunturas cruciales en la historia de la recepción de esta crónica, añado ahora un cuarto momento que no solo la afianza sino también reconoce su importancia global más allá de Perú y Dinamarca. En el 2007, la Nueva corónica y buen gobierno fue declarada documento de patrimonio mundial que debe preservarse como acervo cultural de la humanidad y se la incluyó en el registro Memoria del Mundo de la UNESCO 2 . Este reconocimiento afianza la necesidad de su conservación y, además, ofrece un contraste con los avatares del manuscrito desde el momento en que su autor lo presentó a oficiales virreinales de Lima.

Bien lo sabemos hoy, la obra de Guamán Poma no fue publicada en el siglo XVII como aspiraba su autor y más bien se mantuvo silenciosa y aparentemente invisible por casi trescientos años. No obstante, la difusión de sus contenidos en el siglo xx y, más específicamente, su accesibilidad en la red digital desde el 2001, han impulsado el surgimiento de preguntas sobre el autor y su obra: ¿Quién fue Felipe Guamán Poma de Ayala? ¿Por qué hay tan poca información histórica de este autor y de su proceso de escritura? ¿Fue realmente un descendiente de la familia real inca, como él mismo proclama en su obra o se creó una persona como cronista y príncipe? ${ }^{3}$ ¿Dónde y cómo adquirió la habilidad y los recursos necesarios para escribir y dibujar los contenidos de su extensa obra? ¿Qué pasó con la crónica una vez que el autor la depositó en Lima? ¿Llegó a su destino esperado, la corte del rey de España, y la vio el rey? ¿Obtuvo Guamán Poma alguna respuesta de la Corona? ¿Qué sucedió con el manuscrito para que se encuentre hoy en la Biblioteca Real de Dinamarca? ¿Cómo hizo el viaje de Lima a Madrid y de allí a Copenhague? ¿Y cómo pudo sobrevivir su paso por distintos archivos?

Las respuestas a estas preguntas no son claras ni definitivas hasta el día de hoy. Asombra que tanto un autor cuya información histórica es poca y una obra que se

empaste, muchos detalles se escapan al ojo físico del investigador. De allí la importancia de esta edición digital que se encuentra disponible en las redes públicas y que es administrada por la Biblioteca Real de Dinamarca sin ningún costo para el lector.

2 En el caso del Perú, este reconocimiento se comparte con el acervo de la música colonial andina, también registrada por UNESCO en el 2007 y, en el 2013, los primeros libros impresos del Perú que se publicaron a partir de 1584 así como el registro de viajes de conquistadores españoles al Perú, también llamado Libro Becerro (años 1533-1538).

3 En su libro de 1989, Adorno lo caracteriza como "cronista y príncipe" aludiendo a su calidad de escritor al mismo tiempo que su reclamada nobleza inca. Por su parte, Mercedes López-Baralt lo llama "autor y artista" en sus estudios de 1988 y 1994 en los cuales examina en detalle la producción de sus ilustraciones y su formación como artista visual. 
escribió hace más de 400 años, que no se imprimió en su momento y que contiene cuestionamientos al gobierno español en América, así como una crítica feroz a sus autoridades en las colonias, haya subsistido y que esté a nuestro alcance en el presente. A esto se suman sus silencios y ambivalencias que se manifiestan a través de su carácter bilingüe (español y quechua), su multiplicidad de géneros textuales (historia, sermón, consejería real, tradición oral, entre otros) y los elementos europeos y andinos que se combinan en sus ilustraciones. Teniendo en cuenta estas características que podrían haber atentado contra la vida del manuscrito, cabe preguntarse también por qué este texto desempeña un rol fundamental en la memoria histórica del Perú -y otros países andinos-, así como en la cultura popular actual.

Estas preguntas que se hacen tanto el lector general como el especializado se aúnan a otras acerca de los silencios, omisiones y ambivalencias del texto. Estas sirven, por un lado, para caracterizarlo como una opera aperta andina y, al mismo tiempo, como una obra críptica y enigmática cuyo estudio, como diría Guamán Poma acerca de su propio acto de escribir, nunca se acaba. En tanto opera aperta, la Nueva corónica y buen gobierno genera una relación particular entre el autor y su lector, aun si están separados por más de 400 años. Dicha relación posibilita nuevas lecturas en las cuales las propuestas del cronista acerca de su sociedad y la reflexión del lector sobre el mundo andino y la situación del indio convergen en una complicidad dialógica (Eco, 1962/1985; QuispeAgnoli, 2020, p. 25).

Esta dinámica, a su vez, revela lo que llamo aquí "enigmas de la Nueva corónica y buen gobierno" para referirme a los temas y problemas que generan las preguntas anteriores y otras nuevas que surgen en el proceso de lectura e investigación. Me refiero también a enigmas textuales apuntados por historiadores y críticos textuales que siguen sin respuesta como, por ejemplo, omisiones, silencios, aparentes errores e inconsistencias del texto en contraste con las crónicas que forman parte de la historiografía peruana, crónicas escritas en su significativa mayoría desde el punto de vista europeo y sus cánones ${ }^{4}$. Estos enigmas textuales incluyen confusiones que han sido calificadas como errores en la crónica de Guamán Poma. Ejemplos de lo que parecen ser omisiones voluntarias se expresan en frases como "no lo escribo por evitar prolijidad" o "escribirlo es nunca acabar" (Quispe-Agnoli, 2006, p. 91, 198-199, 257). En otro estudio del 2016, he observado silencios metalingüísticos que se registran especialmente cuando

4 En El cronista indio, Porras Barrenechea califica la obra de Guamán Poma como un texto sin sentido: "Su Nueva crónica y buen gobierno no sólo trata de revivir épocas remotas, casi perdidas para la propia tradición oral en los fondos milenarios de la raza, sino que es también por la confusión y el embrollo de sus ideas y noticias, y por el desorden y barbarie del estilo y de la sintaxis, pura behetría mental" (1948, p. 76). Este juicio de valor se funda en la imposibilidad de reconocer textos escritos sobre el Perú colonial que no siguen el canon de la historia humanista del siglo XvI. 
el autor decide usar términos y frases en quechua sin traducirlos al castellano ni explicarlos en detalle. Este es el caso del uso guamanpumiano de términos como supay (señor del mundo de abajo o Ukupacha), quilca (registro tangible de información) y tocapu (cuadrado con motivos geométricos que indican contenidos y, posiblemente, identidad étnica). Por último, un ejemplo de los "errores" aparentes del cronista se encuentra en la representación, en principio anacrónica, de personajes como Cristóbal Colón y sus compañeros, Francisco Pizarro y Diego de Almagro, entre otros, en su viaje a las Indias y al Perú. En mi estudio sobre estos enigmas textuales, explico que estos "errores" en realidad corresponden a alegorías de eventos registrados en la memoria oral indígena en la cual se integran elementos de códigos andinos que el lector europeo no reconoce. En este sentido, propongo, al final de dicho estudio que escritores como Guamán Poma "pensaban en quechua, probablemente en castellano, miraban su mundo a través de ambas lenguas y escribían en más de una lengua" (2016, p. 34).

Una pregunta constante entre los lectores contemporáneos de la Nueva corónica y buen gobierno es la de su viaje transatlántico y su preservación. Entre los datos y estudios que abordan las interrogantes acerca de las jornadas que siguieron tanto el manuscrito como su autor, se han propuesto explicaciones hipotéticas. El texto de la Nueva corónica y buen gobierno proporciona claves para entender que, una vez terminada su redacción en 1614, Guamán Poma llevó su manuscrito a Lima con el fin de depositarlo ante oficiales virreinales, enviarlo a España y obtener el permiso de su publicación. Lo que sucedió entre este momento y su aparición en el catálogo de fondos de la Biblioteca Real de Dinamarca en el siglo XVIII merece más investigación, así como también la razón de su supervivencia a pesar de los contenidos, controversiales y cuestionables en esta época.

En su ensayo sobre el cronista indio, Raúl Porras Barrenechea comenta las posibles circunstancias de la jornada del manuscrito hasta su llegada a Dinamarca. El historiador señala que el extravío del códice fue una experiencia compartida por otras obras de la época - como las crónicas y relaciones de Juan de Betanzos, Pedro Cieza de León, Joan de Santa Cruz Pachacuti y Pedro Sarmiento de Gamboa, entre otros- y apunta que, a diferencia de otros manuscritos, la Nueva corónica no fue destruida ni quemada sino enviada a España donde probablemente formó parte de la biblioteca imperial "como una expresión curiosa de las civilizaciones primitivas de América" (Porras, 1948, p. 78)5 . Varios estudios sugieren que, a pesar de su crítica acérrima al régimen colonial español en los Andes, las casi 400 ilustraciones incluidas

5 En este punto, Porras Barrenechea sanciona el entusiasmo de Clemente Markham ante el hallazgo de la Nueva corónica en Dinamarca como patética y minimiza el recorrido de la obra a la que califica sarcásticamente como "manuscrito mártir": "El presunto destierro, la fuga o vía crucis del voluminoso códice, no fueron acaso sino la ocasional odisea de tantas otras producciones de la época" (Porras, 1948, p. 78). 
en la crónica contribuyeron a la curiosidad que destacaba Porras Barrenechea y, por lo tanto, a su supervivencia. Según las hipótesis planteadas por estudiosos como Adorno y López-Baralt, estas ilustraciones también han sido causa importante de su popularidad en siglos pasados y hoy como señalo más adelante. Por su parte, el autor de El cronista indio planteó su hipótesis acerca de la conservación de la crónica a partir de una noticia de Gregorio Marañón acerca de la biblioteca del Conde Duque de Olivares, la cual contenía numerosos manuscritos de América. Una buena parte de dicha biblioteca, apuntó Porras Barrenechea, fue adquirida por Cornelius Pederson Lerche, embajador danés en España entre 1650 y 1653, y residente de Madrid hasta 1662. Este personaje habría llevado la colección a Dinamarca y es posible que la crónica de Guamán Poma se encontrara entre sus fondos (Porras, 1948, p. 79).

La investigación exhaustiva que ha hecho Rolena Adorno a lo largo de varios años provee detalles adicionales acerca del recorrido de la obra guamanpumiana. Por un lado, en la introducción a la edición crítica de la Nueva corónica, esta investigadora señala acertadamente que, si bien el autor indígena hizo el viaje de Huamanga a Lima con su manuscrito en 1614, según lo indica el texto mismo, no hay una prueba fehaciente de su entrega a los oficiales virreinales en la Ciudad de los Reyes ese año (Adorno, 1987, p. xlv). Asimismo, no se ha encontrado registro de su llegada a España ni de su traslado a Copenhague. Acerca de la hipótesis de la adquisición de fondos documentales por el embajador danés en el siglo xVII, propuesta por Porras Barrenechea, Adorno señaló en un principio que no se había encontrado aún información que comprobara esta posible ruta. En esta misma introducción editorial de 1987, la crítica llamó la atención sobre las razones que podrían haber llevado la Nueva corónica a la corte danesa. Adorno sugirió entonces que la adquisición de la obra pudo deberse a razones políticas del reino protestante que miraba con atención las actividades del imperio español y la Inquisición en los siglos XVI y XVII. En este contexto, la denuncia de los abusos de los miembros del clero español, así como de los oficiales del imperio que se encuentran en la crónica andina, podían servir para reafirmar al protestantismo en su lucha contra el catolicismo. Una década después, en el marco del anuncio de la digitalización del manuscrito guamanpumiano, Adorno revisó otra vez el tema de los traslados transatlánticos y europeos de la crónica y apuntó que, si bien el catálogo de la biblioteca danesa ofrecía la primera clasificación de la obra entre los años 1784-1786, nuevas investigaciones del bibliotecario danés Harald Ilsøe han comprobado que la crónica se registró en 1729 y, más aún, que el manuscrito fue adquirido a más tardar en 1663, lo cual coincide con el regreso del embajador danés Lerche cuyo rol en el traslado de la crónica andina a Dinamarca fue sugerido por Porras Barrenechea (Guamán Poma, 2001).

En relación con la identidad histórica del autor, la mayoría de la información que se consigna hasta el día de hoy proviene de la misma crónica, aunque otros documentos 
coloniales, que se han publicado en las últimas décadas, también registran su participación y ofrecen información acerca de sus actividades en Huamanga. Guamán Poma nació después de la conquista española. Sus antepasados, como él mismo señala en su obra, eran originalmente de Huánuco, aunque él probablemente nació en Huamanga (Porras Barrenechea, Barnes). Un estudio reciente de Puente Luna (2016) sugiere claves para dilucidar el lugar de nacimiento del cronista y su relación con su medio hermano mestizo, Martín de Ayala, un religioso ermitaño de quien parece que el cronista aprendió a leer y escribir. En los últimos años de la década de 1560, trabajó como asistente e intérprete del extirpador de idolatrías Cristóbal de Albornoz en Lucanas, una localidad ubicada a más de 120 kilómetros al sur de Huamanga. Hacia fines de la década de 1590 se desempeñaba como un administrador indio, probablemente como escribano ya que era un indio ladino (o latino), es decir, su lengua nativa era quechua, sabía leer y escribir en castellano, se declaraba cristiano y estaba hispanizado (Adorno, 1991).

Un documento publicado por Rodolfo Salazar en 1938 registra a Guamán Poma como traductor y testigo en peleas de tierras entre indios y españoles en 1595 (Varallanos, 1979, pp. 210-211). Un año antes, en 1594, aparece de nuevo en otras transacciones relacionadas con tierras y utilizando ya el apelativo Don que lo distinguía socialmente como miembro de una élite (Pereyra Chávez, 1997, pp. 261-270). Asimismo, dos conjuntos de documentos, la Compulsa Ayacucho (Zorrilla) y el Expediente Prado Tello (Prado Tello y Prado Prado) proveen información acerca de su trabajo como notario de indios en la década de 1590 y su litigio con indios chachapoyas a causa de posesión de tierras en Huamanga. Guamán Poma perdió este juicio y hacia 1600 fue desterrado de la zona y condenado a recibir 200 azotes. Es en este momento y, como consecuencia de este dictamen, en el que Adorno sitúa el origen escritural de la Nueva corónica y buen gobierno (1995). Lamentando la corrupción de procuradores, jueces y testigos, Guamán Poma se dio a la tarea de empezar a escribir una "carta al rey" en la cual traería a colación todos los males que afectaban a los indios de los Andes. Esta carta eventualmente se convertiría en la historia de los Andes prehispánicos y coloniales tempranos, en los que el tratamiento de la memoria oral, el trauma de la conquista y colonización españolas sobre el mundo andino y sus consecuencias se expresan en una interacción dinámica entre texto escrito e ilustración visual. De esta manera, Guamán Poma diseñó su obra como un libro ilustrado cuyo manuscrito detentaba todas las convenciones posibles de la cultura impresa para favorecer el permiso de publicación que el cronista anhelaba.

Es posible que, a principios de 1614, el autor haya considerado una primera finalización de su obra. En el capítulo “Camina el autor” (1095 [1105] - 1128 [1138]) Guamán Poma declara que volvió a su casa en Huamanga, probablemente después de cumplir el castigo de su destierro al que había sido condenado en 1600 al perder el litigio de tierras contra los indios chachapoyas. La encontró desolada y vacía, su familia empobrecida y 
sirviendo a otros indios que él consideraba de condición social inferior. Entre marzo y abril de 1614, dejó Huamanga con destino a Lima, acompañado de su hijo, Francisco de Ayala. En este viaje, el autor camina por lo que es hoy la sierra sur y sierra central del Perú, desde Ayacucho a Huancavelica y Junín para luego dirigirse a la ciudad de Lima pasando por la sierra de Huarochirí. En su paso por Castrovirreyna, en Huancavelica, su hijo abandona el viaje. Cuando llega a Huarochirí, escucha de los abusos de Francisco de Ávila, extirpador de idolatrías y propulsor de otro documento fundamental de la memoria andina colonial, el Manuscrito de Huarochirí (1608). Cuando finalmente el autor andino llega a la Ciudad de los Reyes, menciona su paso por el Cercado de Lima y su visita a la iglesia de Santa Clara para rezarle a la Virgen María de la Peña de Francia de la cual se declaraba muy devoto (1125 [1135]) y a las almas del purgatorio. Él mismo declara que alquiló una casa por la que pagaba veinte reales cada mes y que hizo esto no solo para él sino también "para otros pobres que traía consigo por amor de Dios" (1126 [1136]). El viaje a Lima termina dos páginas más adelante (1128 [1138]) en las cuales reafirma su identidad como príncipe inca, nieto del Inca Túpac Yupanqui, e hijo legítimo de Juana Curi Ocllo, a la cual llama coya (reina inca). En este momento de su escritura, resume una vez más sus preocupaciones: el mundo andino está al revés trastocado- a causa de la colonización española, los indios se acaban, los mesticillos abundan "y no hay remedio".

Los estudios sobre el cronista andino y su obra han asumido que, en este viaje a Lima, Guamán Poma llevaba su manuscrito para entregarlo a los oficiales virreinales con el fin de asegurar su envío al rey de España y conseguir el permiso de impresión. No obstante, en el capítulo "Camina el autor" no hay ninguna referencia a esta intención, aunque en la penúltima página de este capítulo, el autor insiste en las razones por las que escribe su crónica: servir a Dios y al rey.

Una carta fechada el 14 de febrero de 1615 en Santiago de Chipao, Huamanga, confirma que el autor volvió a esta zona después de su viaje a Lima. En esta carta, Guamán Poma se dirige una vez más al rey Felipe III y le informa que ha escrito una historia general, sustentada en la memoria oral andina y su propia experiencia de visita, de cuya existencia "podrá dar entera noticia acerca de eso el marqués de Salinas, presidente del Consejo de Indias, que la tiene de mi persona". Además, señala el cronista, si el rey aún no la ha recibido, él está dispuesto a enviársela: "Y así suplico a Vuestra Majestad siendo servido se le mande al Virrey que governase este reino que lo reciba y envíe a buen recaudo a Vuestra Majestad que yo estoy presto de se lo entregar luego que me lo pidiere" (Lohmann Villena, 1945, p. 327). Este es, hasta ahora, el último rastro que conocemos de Guamán Poma de Ayala en los documentos del archivo. Pasarían tres siglos para que se supiera de su existencia y se le publicara. Y cerca de un siglo más 
para ver afianzada su popularidad como medio gráfico de denuncia de la corrupción y males que aquejan a la sociedad peruana.

En su artículo sobre la influencia de las ilustraciones de la obra guamanpumiana en la narrativa gráfica de dibujantes peruanos contemporáneos como Miguel Det y Markus Ronjam, Juan Valle Quispe apunta el tratamiento visual y gráfico de la desigualdad de poderes en la sociedad peruana actual y la crítica a su clase política cumpliendo así una función de denuncia de manera similar a la planteada por Guamán Poma hace cuatrocientos años. Estos artistas se suman a otros reunidos en colecciones de narrativas gráficas e historietas como Nueva crónica del Perú, siglo Xx (Macera y Forns, 2000), Nueva crónica del Perú, siglo XXI (Forns, 2003), Nueva crónica del Perú 2000-2005 (Forns y Vega, 2006) y Novísima crónica i mal gobierno (Det, 2011). Estos ejemplos muestran que la vigencia de la Nueva corónica y buen gobierno da lugar no solo a estudios académicos sino también invita a relecturas de escritores y artistas contemporáneos que recogen las inquietudes y preocupaciones de la sociedad peruana actual y las plasman en sus obras.

Aunadas al acceso permitido por la disponibilidad digital en redes, las obras de estos autores y artistas contribuyen así a la difusión de Guamán Poma y su crónica y a la construcción de un imaginario colectivo que se nutre de sus imágenes. Dos ejemplos recientes de la popularidad de la Nueva corónica se encuentran en el panfleto con instrucciones para evitar el contagio frente a la pandemia del COVID-19, creado por estudiantes de la Facultad de Historia de la Universidad Mayor de San Andrés de Bolivia en el 2020 (Churampi Ramírez) y la "carlincatura" de la situación política peruana a propósito de la campaña presidencial del año $2021^{6}$. En esta última, el artista gráfico peruano Carlín utiliza elementos de dos dibujos de Guamán Poma de Ayala (https://larepublica.pe/ carlincatura/2021/04/20/carlincatura-de-hoy-martes-20-de-abril-de-2021/) cuyos trazos reconoce el lector contemporáneo enseguida. Ambos dibujos se encuentran en el capítulo de las guerras civiles entre conquistadores españoles. En el primero, Sebastián de Alcázar y Hernando Pizarro acometen contra el Inca Atahualpa en Cajamarca (Figura 1: http://www5.kb.dk/permalink/2006/poma/384/es/text/). Los rostros de tres personajes de la política peruana se superponen a los de estos personajes: Keiko Fujimori (candidata a la presidencia del Perú) y Mario Vargas Llosa (escritor) ocupan los lugares de Pizarro y Alcázar respectivamente mientras que Pedro Castillo (candidato a la presidencia del

6 Las "carlincaturas" son caricaturas de personajes de la política peruana creadas por el artista gráfico Carlos Tovar (Carlín). La carlincatura que menciono aquí fue publicada en el diario La República el 21 de abril del 2021 a propósito de los resultados de la primera vuelta de las elecciones presidenciales del Perú. Pedro Castillo, del Partido Perú Libre, y Keiko Fujimori, del Partido Fuerza Popular, obtuvieron la mayor cantidad de votos y pasaron a la segunda vuelta electoral que se llevó a cabo el 6 de junio del 2021. A los pocos días de los resultados de la primera vuelta electoral, el escritor peruano Mario Vargas Llosa, Premio Nobel de Literatura 2010, manifestó públicamente su apoyo a la candidatura de Keiko Fujimori. 


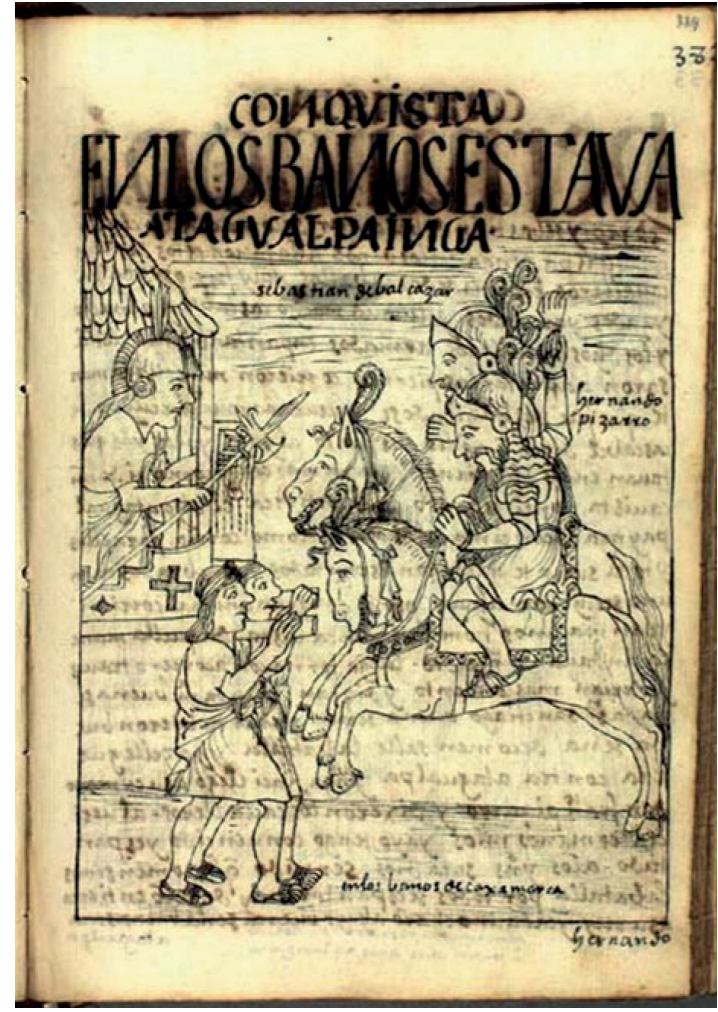

Figura 1: Nueva corónica y buen gobierno, p. 384. Biblioteca Real de Dinamarca

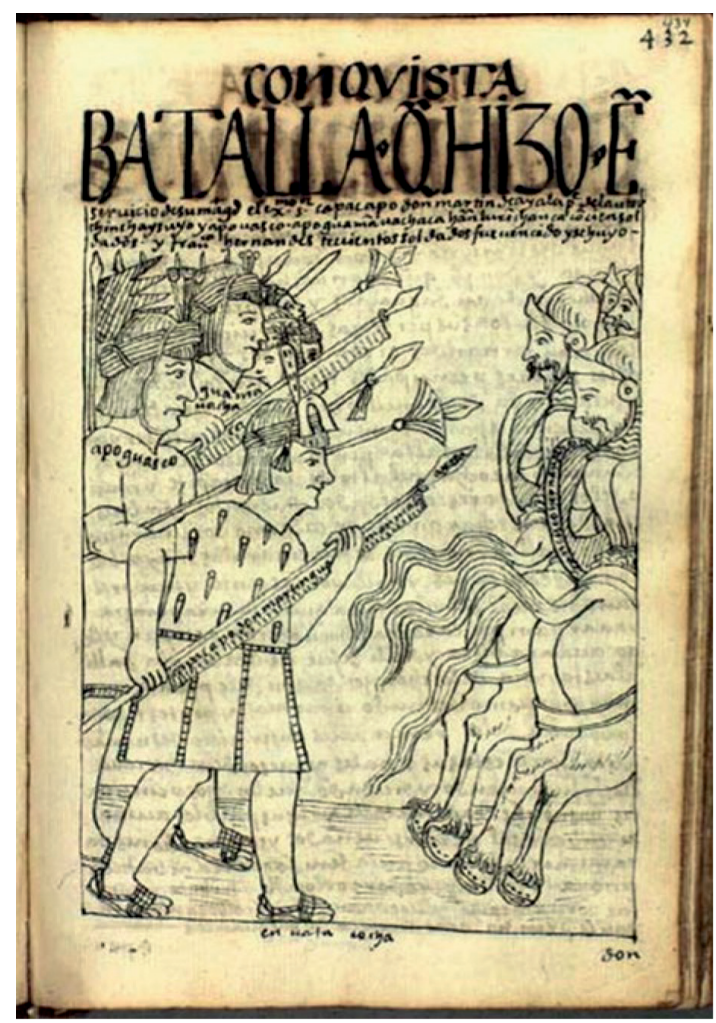

Figura 2: Nueva corónica y buen gobierno, p. 434 Biblioteca Real de Dinamarca.

Perú) se coloca en una posición semejante a la del Inca Atahualpa en el dibujo. A estos elementos se añaden soldados del ejército inca que aparecen en el otro dibujo de la Nueva corónica (Figura 2: http://www5.kb.dk/permalink/2006/poma/434/es/text//), en el cual aparece don Martín de Ayala, padre del autor y señor principal andino, en batalla contra Francisco Hernández Girón, rebelde contra el rey de España y traidor al imperio.

La Nueva corónica y buen gobierno de Felipe Guamán Poma de Ayala es una obra enigmática con múltiples niveles de lectura que se activan según la posición desde la que se lee. Textualmente rica, desafiantemente críptica y provocativamente ambivalente, exige el manejo de códigos diglósicos tanto a nivel lingüístico como cultural e histórico para disfrutarla. Comparte estas características con la idiosincrasia de la sociedad peruana actual y esta es probablemente la razón por la que, a pesar de su invisibilidad de tres siglos, se mantiene como un repertorio de expresión popular. Quizás el factor que contribuyó a su subsistencia, en una jornada global a través de los siglos, es también una de las razones que la convierten en un texto cuya vigencia vence el paso del tiempo. 


\section{OBRAS CITADAS}

Adorno, R. (1989) Cronista y príncipe: la obra de don Felipe Guamán Poma de Ayala. Pontificia Universidad Católica del Perú, Fondo Editorial.

Adorno, R. (1991) “Images of Indios Ladinos in Early Colonial Peru”. En K. Andrien y R. Adorno (Eds). Transatlantic Encounters: Europeans and Andeans in the Sixteenth Century. (1995) "La génesis de la Nueva corónica y buen gobierno de Felipe Guamán Poma de Ayala" Taller de Letras 23, 9-45.

Barnes, M. (1999, 19 de septiembre). "La Nueva corónica y buen gobierno fue escrita por un residente de Lucanas" [Ponencia] Guamán Poma de Ayala y Blas Valera: tradición andina e historia colonial, Roma, Italia.

Churampi Ramírez, A. (2020)."'A versiahora mesiguenninguneando':resistenciay rebelión desde Guamán Poma de Ayala" El Nieuwe Acá. https://elnieuweaca.com/2020/08/31/a-ver-siahora-me-siguen-ninguneando-resistencia-y-rebelion-desde-guaman-poma-de-ayala/

Det, M. (2011). Novísima corónica i mal gobierno. Contracultura.

Eco, U. (1985). Obra abierta. Ariel. (Trabajo original publicado en 1962).

Forns, S. (Ed). (2006). Nueva crónica del Perú, 2000-2005. El Santo Oficio.

Forns, S. e I. Vega. (2003). Nueva crónica del Perú, siglo XxI, 2000-2003. Amarilys.

Guamán Poma de Ayala, F. (1936 [1615]). Nueva corónica y buen gobierno (codex péruvien illustré) (edición de P. Rivet). Institute d'Ethnologie.

Guamán Poma de Ayala, F. (1987 [1615]). Nueva crónica y buen gobierno. (Edición de J. V. Murra, R. Adorno y J. Urioste). Historia 16, 3 Vols.

Guamán Poma de Ayala, F. (2001 [1615]). El sitio de Guamán Poma. GKS 2232 4.: Guaman Poma, Nueva corónica y buen gobierno. Det Kongelige Bibliotek. http://www5.kb.dk/permalink/2006/poma/info/es/frontpage.htm

Lohmann Villena, G. (1945). “Una carta inédita de Huamán Pom de Ayala.” Revista de Indias 20, 325-327.

López-Baralt, M. (1988). Ícono y conquista. Hiperión.

López-Baralt, M. (1994). Guamán Poma, autor y artista. Pontificia Universidad Católica del Perú, Fondo Editorial.

Macera, P., y S. Forns. (2000). Nueva crónica del Perú, siglo xx. Congreso del Perú, Fondo Editorial.

Pereyra Chávez, N. (1997) "Un documento sobre Guamán Poma existente en el Archivo Departamental de Ayacucho", Histórica. 21 (2), 261-270.

Pietschmann, R. (1913) "Relación sobre la crónica ilustrada por el indio peruano don Felipe Huamán Poma de Ayala" Proceedings of the XVIII International Congress of Americanists (1912). Harrisons \& Son, pp. 510-521. 
Pietschmann, R. (1980). “Nueva corónica y buen gobierno de Don Felipe Guaman Poma de Ayala, eine peruanische Bildershandschrift". En Nachrichten von der königlichen Gesellschaft der Wissenschaften zu Göttingen. Weidmannsche Buchhandlung, pp. 637-659.

Prado Tello, E., y A. Prado Prado (Eds.) (1991). Phelipe Guamán Poma: Y no ay rremedio... Centro de Investigación y Promoción Amazónica.

Puente Luna, J. C. (2016). “El capitán, el ermitaño y el cronista. Claves para establecer cuándo nació el autor de la Nueva corónica y buen gobierno". En J. P. Husson. Guamán Poma y la escritura de la Nueva corónica. Pontificia Universidad Católica del Perú, Fondo Editorial, pp. 233-246.

Porras Barrenechea, R. (1948). El cronista indio Felipe Huamán Poma de Ayala (¿1534-1615?). Editorial Lumen.

Quispe-Agnoli, R. (2006). La fe andina en la escritura. Identidad y Resistencia en la obra de Guamán Poma de Ayala. Universidad Nacional Mayor de San Marcos, Fondo Editorial.

Quispe-Agnoli, R. (2016) “Acerca de silencios, omisiones y 'errores' en la obra de Guamán Poma de Ayala... el conpañero de Colum a las indias". En Guamán Poma de Ayala. Las travesías culturales. M. Mamani (Ed.). Pakarina Ediciones, pp. 17-36.

Quispe-Agnoli, R. (2020). "Escribirlo es nunca acabar: Cuatrocientos cinco años de lecturas y silencios de una Opera Aperta andina". Letras. Revista de investigación de Letras y Ciencias Humanas, 91(133), 5-34.

UNESCO. (2007). "El Primer Nueva Coronica y Buen Gobierno." Memoria del Mundo. Inscripciones en el registro realizadas en el 2007. http://www.unesco.org/new/en/communication-and -information/memory-of-the-world/register/full-list-of-registered-heritage/ registered-heritage-page-3/el-primer-nueva-coronica-y-buen-gobierno/

Valle Quispe, J. (2016) “Contra la forclusión: la herencia gráfica y política de Felipe Guamán Poma de Ayala en dos dibujantes peruanos contemporáneos". M. Mamani (Ed.). Guamán Poma de Ayala. Las travesías culturales. Pakarina Ediciones, pp. 17-36, 247-268.

Varallanos, J. (1979). Guamán Poma de Ayala: cronista y precursor. G. Herrera.

Zorrilla, J. (1977). “La posesión de Chiara por los indios chachapoyas”. Wari 1, pp. 49-64. 